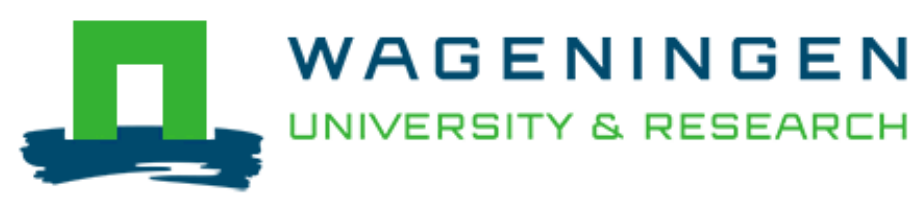

Gendered climate change adaptation practices in fragmented farm fields of Gamo Highlands, Ethiopia

Cholo, T. C., Peerlings, J., \& Fleskens, L.

This is a "Post-Print" accepted manuscript, which has been published in "Climate and Development"

This version is distributed under a non-commercial no derivatives Creative Commons

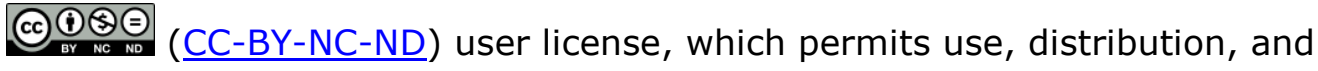
reproduction in any medium, provided the original work is properly cited and not used for commercial purposes. Further, the restriction applies that if you remix, transform, or build upon the material, you may not distribute the modified material.

Please cite this publication as follows:

Cholo, T. C., Peerlings, J., \& Fleskens, L. (2019). Gendered climate change adaptation practices in fragmented farm fields of Gamo Highlands, Ethiopia. Climate and Development. https://doi.org/10.1080/17565529.2019.1618234 


\title{
Gendered climate change adaptation practices in fragmented farm fields of Gamo Highlands, Ethiopia
}

\author{
Tesfaye C.Cholo ${ }^{\mathrm{a}, \mathrm{c},},{ }^{*}$, Jack Peerlings ${ }^{\mathrm{b}}$, Luuk Fleskens ${ }^{\mathrm{a}}$ \\ ${ }^{a}$ Wageningen University and Research, Soil Physics and Land Management Group, Wageningen, The Netherlands \\ b Wageningen University and Research, Agricultural Economics and Rural Policy Group, Wageningen, The \\ Netherlands \\ ${ }^{c}$ Ethiopian Civil Service University, Department of Development Economics, Addis Ababa, Ethiopia \\ * Corresponding author at: Wageningen University and Research, Soil Physics and Land Management Group, \\ Droevendaalsesteeg 4, 6708PB Wageningen, The Netherlands \\ Email addresses: tesfayechofana@yahoo.com (Tesfaye C. Cholo)
}

\begin{abstract}
The objective of this study is to assess the existence of gendered climate change adaptation practices of smallholder farmers in the Gamo Highlands of Ethiopia. We hypothesized that smallholders' adaptation practices are gendered because of land fragmentation and gendered division of labour. To explore this, we considered sustainable land management practices as a tool for sustainable adaptation and assessed the effect of land management practices deployed and land fragmentation on intra-household time allocation. The results indicate that although land fragmentation increased hours worked by men and women significantly, fragmentation increased the working hours of men more than women. Application of a larger number of sustainable land management practices increases the mean working hours of women, but leaves unaffected the working hours of men, implying that adaptation practices are gender-biased. Therefore, this study can guide land management decisions by pointing out that fragmentation results in long working hours and adaptation practices may disproportionately affect women.
\end{abstract}

Key word: Land management, fragmentation, sustainable, gendered, work division, JEL Q15 \& $\mathrm{J} 16$ 


\section{Introduction}

Agriculture is the sector most affected by climate change in developing countries (Kotir, 2011; Kurukulasuriya \& Mendelsohn, 2008), and the majority of the poor depend on agriculture for their livelihood in sub-Saharan Africa (Jayne et al., 2003). The poor (Pachauri \& Meyer, 2014; Thomas \& Twyman, 2005) and women in subsistence farming are the most affected group within agricultural households (Cannon, 2002; Parry, Canziani, Palutikof, van der Linden, \& Hanson, 2007) because of the social division of responsibilities and differences in access to and control over resources (Doss, 2001; Marlene \& Henry, 2002; Murray, Gebremedhin, Brychkova, $\&$ Spillane, 2016). Moreover, women and the poor are underrepresented in studies, negotiations and policies related to addressing climate change impacts (Jerneck, 2018; Minu \& Ulrike, 2009). Climate change tends therefore to exacerbate existing gender inequality, causing women to face larger negative impacts of climate change than men (Margaret. Alston, 2013; Cannon, 2002). Gender inequality is defined as prejudicial treatment of individuals or groups because of their gender (Shastri, 2014). For instance, a changing climate affects women more than men in most cases (Cannon, 2002; Denton, 2002; Peralta, 2009).

Adaptation to climate change enhances food security (M. Burke \& Lobell, 2010; Di Falco, Veronesi, \& Yesuf, 2011; Jerneck, 2018), reduces vulnerability to climate change impacts and reinforces resilience (Field, 2012). However, benefits and costs of adaptation practices can be unfairly distributed between men and women (Björnberg \& Hansson, 2013). Moreover, the impacts of adaptation practices are not gender-neutral (Margaret Alston, 2011; Jerneck, 2018), like gender differences in climate change impacts (Margaret. Alston, 2013; Jin, Wang, \& Gao, 2015; Terry, 2009). Although earlier studies assess gendered adaptation practices and gender gets an increasing attention in the climate change adaptation, resilience and vulnerability literature, this literature remains in its infancy (Bunce \& Ford, 2015). For instance, alteration of gender roles was used in the Philippines as a strategy to adapt to climate change. However, although the alteration of gender roles increased women's access to resources, it burdened women more as they became both farm managers and caretakers of family welfare (Tatlonghari \& Paris, 2013). Smucker and Wangui (2016) observed gendered knowledge about adaptation practices in Tanzania, Jin et al. (2015) point out gender differences in the choice of 
climate change adaptation measures in China and Jerneck (2018) observed adaptation effects also differ between men and women because of differences in their respective social roles and responsibilities and control over resources and Mersha and Van Laerhoven (2016) look at gendered barriers to adaptation practices in Ethiopia. Moreover, Demetriades and Esplen (2008) indicate the inadequacy of scientific investigations explaining unequal sharing of benefits and burdens of climate change adaptation endeavours. This study contributes to climate change adaptation literature in agriculture by explaining gendered drawbacks of adopting sustainable land management practices in fragmented farmlands to deal with climate change. Moreover, the study offers useful insights into how adaptation responses to climate change cause different outcomes due to pre-existing gender inequalities e.g., gender-based division of labours.

Hung, MacAulay, and Marsh (2007) and Kawasaki (2010) describe land fragmentation (LF) as cultivation of multiple separated parcels. Multiple separated plots per owner can result in plots being far apart from each other and from home. In Ethiopia LF is exogenous to farmers, as there is no land market and farmers have inherited already fragmented plots. LF is affecting working hours of both men and women and how time is allocated between different tasks (McCall, 1985). Moreover, LF influences the use of sustainable land management practices (Nigussie et al., 2017). Sustainable land management can be defined as an adaptive strategy that jointly enhances environmental quality and farmers' livelihood (Fernandes \& Burcroff, 2006). Plus, it is expected that fragmentation is worsening the inequity of sharing the loads of adaptation endeavours between men and women. For instance, manure use and tree planting on multiple plots are adaptation practices in Gamo communities in the Ethiopian highlands that potentially result in extra commuting time, higher workloads and longer working hours for women compared to men. Adding manure to remote plots and collecting firewood from fragmented and faraway plots are tasks mostly undertaken by women in these communities. As a result, women work longer hours and lose time that otherwise would be allocated to rest and leisure, which leads to more time poverty for women than for men (Bardasi \& Wodon, 2006; Kes $\&$ Swaminathan, 2006). Time poverty occurs when workers do not have enough time for rest and leisure after considering time used for production and domestic work (Bardasi \& Wodon, 2006). Additionally, land fragmentation decreases efficiency of crop production (Manjunatha, Anik, Speelman, \& Nuppenau, 2013) and lowers food production per hectare 
(Rahmana \& Rahman, 2008). This affects women more than men due to their reproductive roles (Doss, 2001); as an illustration, women are more responsible for household welfare (i.e., nourishing children and labour force) in Gamo communities.

This study was conducted in the Gamo Highlands of Ethiopia, where the land is fragmented and farmers are responding to climate change and variability they have observed (Bryan, Deressa, Gbetibouo, \& Ringler, 2009). The purpose of the study is to explore the existence of gendered climate change adaptation practices in agriculture amongst Gamo communities, i.e., whether adaptation practices lead to incremental inequality in time poverty. The research questions addressed in this paper are: i) Does land fragmentation increase hours allocated to work? ii) Does land fragmentation lead to more hours allocated to work by women than by men? iii) Do sustainable land management practices result in more hours allocated to work by women than by men?

The outline of the paper is as follows: Section 2 and 3 present the study area and description of data and the theoretical framework, respectively. Section 4 explains the empirical model. Section 5 discusses the results, and the final section presents the conclusions.

\section{The study area and data collection}

The study region is the Gamo Highlands, a heterogeneous mountainous landscape located in southwest Ethiopia, high above and east of two lakes, Abaya and Chamo. Seasonal variation of farm tasks causes farmers to work longer hours per day during peak labour seasons (i.e., seasons with high work pressure). Both women and men work long hours, more to meet their basic needs than for profit motives because of their low human capital status and lack of sufficient access to agricultural technologies (such as fertilizer and quality seed). The gender division of labour enforced by custom in the Gamo communities causes women to allocate more hours per week to work than men, which is consistent with the national average in which women with 8.17 hours work more than men that work 7.10 hours per day (United Nations, 2015, 2018) and leads to power asymmetries in access to and control over the factors of production (Doss, 2001). Moreover, women and men have separate roles and duties and decision-making power, leading to further gender inequality in the Gamo communities. Women undertake both farm work and domestic work, but men are hardly involved in domestic tasks such as fetching water, collecting 
fodder and cooking for the family. In addition, women work longer hours than men not only because of the domestic division of labour, but also because some family farm activities are solely performed by women. For instance, composting and applying manure are productive activities solely performed by women. Moreover, land management practices to cope with climate change, such as planting indigenous trees and applying more manure, further exacerbate the already high time burden of women. The time demand for these tasks may be especially significant in the case of multiple plots at a distance from home and from each other, and this is expected to increase women's hours allocated to work considerably. That is, adaptation on fragmented farms disproportionately affects women as it requires them to commute more from home to dispersed farm fields and to work longer hours.

The household level primary data used for this study was collected in the year 2015 from three kebeles (the lowest-level administrative unit) namely: Done, Haila and OcholoBadiga in Dita woreda (the next highest-level administrative unit). These kebeles were selected because the local government's ongoing geographic data inventory is fully complete for these kebeles. A stratified random sampling technique was used to select farmers from these kebeles, based on multiple plot ownership and agri-environmental zones. Quantitative data were collected from 297 male and female household heads. For each household, both the husband and wife were interviewed; in cases of a female-headed household this was the woman leading the farm and in all cases her son. There were only 28 female household heads out of 297 households in the sample. There were no households headed by unmarried men. In addition to household data collected, hours allocated to work by the husband and wife (i.e. hereafter men and women ${ }^{1}$ ) and their demographic characteristics such as age and education were inventoried as well as the perceived work burdens of men and women for the peak labour seasons (i.e., harvesting and planting) and the off-peak season at one moment in time by specifying the seasons for respondents. The LF indices were calculated from spatially-explicit secondary data on household

\footnotetext{
${ }^{1}$ Women comprise heads of female headed households and wives
} 
plots that was collected by experts employed by the local government using global positioning system (GPS) devices to certify land use rights.

\section{Theoretical framework}

Time is a scarce resource that can be allocated to work and leisure. More time spent on work reduces leisure and hence leads to higher time poverty and work burden (Bardasi \& Wodon, 2006). Work-related stressful experiences contribute to depression and psychological disorders (Tennant, 2001), and working long hours may cause various health problems (R. Burke \& McAteer, 2007), Time scarcity also affects food choices, which can lead to serious health problems (Jabs \& Devine, 2006). Moreover, the burden of competing tasks on an individual's time constrains that individual's choice of how to allocate their time, increases the intensity of work and creates tradeoffs among different tasks (Kes \& Swaminathan, 2006). Time poverty contributes to income poverty in several ways (see Burchardt (2008) for empirical evidence). First, participation in non-market works that are labour intensive and unproductive domestic and subsistence agricultural works ${ }^{2}$ reduces time that could be allocated for productive activities and therefore income. Second, because of the gender division of labour, particularly women are less likely to participate in income generating activities. Third, time poverty impedes human capital development by limiting the individual's access to education and skill development that could result in better paid jobs (Burchardt, 2008; Kes \& Swaminathan, 2006). Time poverty is positively related to the hours worked. For this we argue that adaptation on fragmented and remote farm fields leads to time poverty (e.g., decreases time available for gainful activities and leisure) by increasing time of commuting and requiring more energy and time, particularly for women who are responsible for labour intensive adaptation practices and domestic work. In this research the number of hours worked per week by men and women in three different seasons is used to capture the work burden and time poverty associated with adaptation endeavours and LF.

2 These unproductive works are laborious activities with poor returns as they do not result in marketable output and women are not paid for their labour. 
Worked hours are the sum of paid and unpaid work following the classification of both used by the United Nations (2005). Paid work is divided into off-farm and on-farm work, the latter including subsistence production on family farms. Unpaid work consists of mainly domestic work. The harvesting and planting seasons are considered to be the two peak seasons because work pressure is high, while the off-peak season is the season following the harvesting season when work pressure is relatively low in the Gamo Highlands.

\section{Time allocated to work}

Men and women in Gamo communities typically work six days a week and work longer hours per day than the International Labour Organization (ILO) standard, (i.e., 48 hours per week for industry workers) (ILO, 1921). Moreover, the number of hours allocated to work is likely to be gender specific. Time allocation is especially relevant in peak labour seasons (i.e., planting and harvesting seasons) when time is most scarce. On average, our data show that women and men allocate 89 and 70 hours per week to work during the harvesting season, respectively, and during the planting season the mean working hours of women and men, respectively, are 87 and 71 hours per week. Also during the off-peak season women allocate more hours to work than men, on average, 77 hours versus 62 hours per week, respectively. The hypothesis that women and men on average allocate equal time to work was rejected at the $1 \%$ significance level for all seasons. Moreover, $89 \%$ of men and $90 \%$ of women involved in the survey opined that women work more hours than men. These findings are consistent with Wright (2007) and Craig (2005). The reason for the gender gap in hours worked is that women are responsible for most domestic work in Gamo communities.

Although the vast majority (91\%) of household heads interviewed were men, close to two-thirds of the male-headed households reported that harvesting crops from and transporting heavy manure to remote plots results in more working hours for women than for men. Men were accountable for farm production (i.e. for harvesting and planting), while women were responsible for both domestic work and farm production. Meanwhile, 95\% of the household heads said that women were responsible for adding manure to soils and $90 \%$ reported that women were responsible for collecting and carrying fodder and hay from various plots to the homestead. Meanwhile, women are equally responsible for activities done by men as well as for 
activities solely done by women, including cooking and supplying food to farm workers. Next we discuss the variables that can explain the number of hours worked by men and women.

Table 1. Summary statistics of variables

\begin{tabular}{|c|c|c|c|c|c|c|}
\hline Variable & Description of variables & $\%$ & mea & SD & $\min$ & $\max$ \\
\hline \multicolumn{7}{|c|}{ Hours allocated to work by spouses ${ }^{3}$} \\
\hline planting & Hours allocated to work per week in planting season & & 78.7 & 16.1 & 0 & 108 \\
\hline harvesting & Hours allocated to work per week in harvesting season & & 79.5 & 16.8 & 0 & 114 \\
\hline work-off & Hours allocated to work per week in off-peak season & & 69.9 & 18.8 & 0 & 114 \\
\hline \multicolumn{7}{|c|}{ SLM practices (dummy, $1=$ yes) } \\
\hline seed & Quality seed use & 76 & & & & \\
\hline manure & Manure use & 94 & & & & \\
\hline indigenous & Indigenous tree planting & 74 & & & & \\
\hline terrace & Stone terrace or soil bund application & 84 & & & & \\
\hline legume & Legume barley rotation & 86 & & & & \\
\hline enset & Expansion of enset planting & 59 & & & & \\
\hline new-crop & New crop introduction & 59 & & & & \\
\hline diversify & Crop diversification & 59 & & & & \\
\hline SLMn & Number of SLM practices applied & & 6.15 & 1.87 & 0 & 8 \\
\hline \multicolumn{7}{|c|}{ Land fragmentation indicators } \\
\hline SFI & Simpson index for land fragmentation & & 0.85 & 0.1 & 0 & 0.97 \\
\hline distance 2 & Sum of non-overlapping distance from home to plots & & 2.6 & 1.6 & 0.1 & 8.7 \\
\hline AEZ & 1 if a farmer farms in two distinct agro-ecological zones & 36 & & & & \\
\hline \multicolumn{7}{|c|}{ Socioeconomic characteristics } \\
\hline genderh & 1 if gender of household head is male & 91 & & & & \\
\hline literacy & 1 if household head can read and write & 21 & & & & \\
\hline age & Age of a husband or wife & & 49.6 & 16 & 15 & 98 \\
\hline family & Family members under age 10 & & 2.4 & 1.6 & 0 & 9 \\
\hline labour & Active family labour size (age 15-64) & & 4.1 & 2.4 & 0.2 & 16.5 \\
\hline tlu & Number of tropical livestock units & & 2.5 & 2.7 & 0 & 22.9 \\
\hline income & Amount of off-farm income (thousands of birr) & & 1.6 & 2.7 & 0 & 20 \\
\hline
\end{tabular}

Source: Survey data

${ }^{3}$ Or woman and son in case of female-headed households. 


\section{Land fragmentation indicators}

Land fragmentation is measured such that it captures three important dimensions of fragmentation. The measures used are the non-overlapping distance from home to all plots owned by a farm was measured using GPS devices, the number of plots, having plots in different agro-ecological zones, namely midland and highland (see Table 1) and the Simpson index for land fragmentation. Hung et al. (2007) defined the Simpson index as $\left[1-\left(\sum_{i=1}^{n} a_{i}^{2} / A^{2}\right)\right]$ where $a_{i}$ is the area of the $i^{t h}$ plot in hectares, and $A$ is the farm size in hectares, which equals the sum of the area of all $n$ plots of the farm, $\sum_{i=1}^{n} a_{i}$. The value of the index ranges from 0 for ownership of a single plot to 1 for ownership of several plots. The mean farm size in the study area was 1.7 hectares. On average, a household owned 21 plots and the number of plots ranged from 1 to 80 plots. These LF indices are expected to increase hours allocated to work per week for men and women by increasing commuting time from home to plots and between plots. While LF expected to increase working hours of women more than of men because of gender roles and division of labour.

\section{Sustainable land management practices}

SLM practices considered in the study were selected in a number of steps. First, a survey was made of 13 potential SLM practices based on their importance to soil and water conservation and suitability for local conditions. Second, farmers were asked about whether or not they have altered/used these SLM practices to adapt to the climate change impacts and variability they have perceived in the last 25 years. Climate change and variability indicators are changes in temperature and precipitation while climate change impacts farmers observed are crop productivity and soil erosion changes. Farmers' observed climate change impacts and variability over the last 25 years were used to measure climate change and variability and impacts since we were unable to find long-term meteorological data for the study area. However, farmers' perceptions of climate change and variability were consistent with trends of meteorological data in Ethiopia and sub-Saharan Africa (Bryan et al., 2009; Bryan et al., 2013; Maddison, 2007). If farmers respond to climate change, they are perceived as adapters. Interestingly, almost 95\% percent of the farmers in this study are changing SLM practices to deal with climate change and 
variability. Finally, eight SLM practices correlated with the farmers' perception of climate change and variability at the $10 \%$ significance level were considered for this study (see Table 2). Interestingly, of these 8 SLM measures, more than $82 \%$ of the farmers applied at least 4 SLM practices to adapt to the changing climate. The number of SLM practices (SLMn) applied per farm is obtained by adding all SLM practices used on a farm. For instance, if a given farm applied five SLM practices out of the eight practices indicated in Table 1, the SLMn value of the farm is 5 and so on. We assume that SLMn will increase women's working hours more than men's working hours for each of the seasons.

\section{Socioeconomic characteristics}

Socioeconomic factors affecting hours worked comprise gender, age, education, family labour size, off-farm income and number of children (E.-R. Birch, 2005; R. E. Birch, Le, \& Miller, 2009; R. Burke \& McAteer, 2007; Wright, 2007). Evidences indicated that women work longer than men (United Nations, 2015). Moreover, women are commonly caretakers of children in Gamo communities-hence the number of family members under age 10 is expected to increase hours allocated to domestic work for women more than for men. When the available farm work can be distributed to more people the workload goes down, thus family labour availability is expected to decrease the hours worked per week by both men and women and is expected to decrease their time poverty. Off-farm incomes are mostly generated by men who migrate to urban areas, and this may increase the working hours of women (Mu \& Van de Walle, 2011) since domestic work and farm tasks are left to the women.

\section{Empirical model}

To determine how LF and SLM practices affect the working hours of men and women in each season, we specify the following time allocation model:

$$
\begin{gathered}
\ln y_{i g s}=\alpha_{g s}+\sum_{j=1}^{3} \beta_{j g s} \ln L F_{i j}+\gamma_{g s} S L M n_{i}+\sum_{r=1}^{4} \delta_{r g s} \ln x_{i r}+\sum_{u=1}^{2} \rho_{u g s} d_{i u}+\varepsilon_{i g s} \\
g=1,2 ; \quad s=1,2,3
\end{gathered}
$$


where $y_{i g s}$ is the number of hours worked by individual $i$ of gender $g$ in season $s, L F_{i j}$ is the LF indicator $j$ for individual $i, S L M n_{i}$ is the number of SLM practices applied by individual $i$, $x_{i r}$ is socio-economic characteristic $r$ of individual $i$, and $d_{i u}$ is a dummy variable for demographic characteristic $u$ of individual $i . \alpha_{g s}, \beta_{j g s}, \gamma_{g s}, \delta_{r g s}$ and $\rho_{u g s}$ are coefficients to be estimated. $\varepsilon_{i g s}$ is the error term; $g=1$ is woman and $g=2$ is man; and $s=1$ is planting season, $s=2$ is harvesting season and $s=3$ is off-peak season. For LF indicators: $j=1$ is Simpson index, $j=2$ is distance and $j=3$ is agro-ecological zone.

So we have a system of 6 equations, i.e., 2 gender types (g) times 3 seasons (s). We assume the errors to have zero mean and to be independent across individuals, but for a given individual errors are assumed to be correlated across equations. The justification for this is that we expect the same unobservable factors to play a role in each of the equations. In such a case, although OLS is a consistent estimator, it is not efficient (Adrian Colin Cameron \& Trivedi, 2009; Zellner, 1962). To increase the efficiency of the estimation, we use Seemingly Unrelated Regression (SUR) to estimate the model, as suggested by A Colin Cameron and Trivedi (2005) and Zellner (1962). To get heteroskedasticity-robust standard errors for the SUR estimator, we employ bootstrap regression as suggested by Adrian Colin Cameron and Trivedi (2009). Moreover, the Breusch-Pagan Lagrange test is applied to test the null hypothesis that states that the error terms across the six equations are independent.

To show whether LF affects hours worked by women and men differently, we tested four hypotheses using a likelihood ratio test by imposing restrictions on parameters across equations (Adrian Colin Cameron \& Trivedi, 2009). The first null hypothesis, $A_{1}$, states that each of the LF indicators does not affect hours allocated to work by women for all seasons. For instance, the Simpson index does not affect hours worked by women during the planting season (i.e., $\left.A_{1}: \beta_{111}=0\right)$ and so forth. The second null hypothesis, $A_{2}$, states that each of the LF indicators does not affect hours allocated to work by men for all seasons. The third null hypothesis, $A_{3}$, states that each of the LF indicators has the same impact on the mean hours worked by men and women in the same season. The fourth null hypothesis, $A_{4}$, states that each of the LF indicators has an equal impact on hours worked by women throughout the seasons. 
To show whether SLM practices affect the working hours of women differently than those of men, we tested a further four hypotheses using a likelihood ratio test. The fifth null hypothesis, $A_{5}$, states that the number of SLM practices applied does not affect hours allocated to work by women for all seasons. The sixth null hypothesis, $A_{6}$, states that the number of SLM practices applied does not affect hours allocated to work by men throughout the seasons. The seventh null hypothesis, $A_{7}$, states that the number of SLM practices deployed has the same impact on the mean hours worked by men and women in the same season. The eighth null hypothesis, $A_{8}$, states that the number of SLM practices applied has the same impact on working hours of women across seasons.

\section{Results and discussion}

This section presents the estimation results of the SUR model in Table 2 and 3 and hypotheses tests in Table 4 and 5. There are 295 observations in the regression because of the exclusion of two individuals, a man and a woman, that worked zero hours per week in all three seasons. We have estimated six equations using SUR. Goodness-of-fit $\left(R^{2}\right)$ and chi-squared $\left(\chi^{2}\right)$ values of each equation are indicated at the bottom of Table 3 .

\section{Insert Table 2}

Table 2: The correlation matrix of residuals

\begin{tabular}{l|rrrrrr}
\hline & $\begin{array}{r}\text { Planting } \\
(\text { men) }\end{array}$ & $\begin{array}{r}\text { Planting } \\
\text { (women) }\end{array}$ & $\begin{array}{r}\text { Off-peak } \\
\text { (men) }\end{array}$ & $\begin{array}{r}\text { Off-peak } \\
\text { (women) }\end{array}$ & $\begin{array}{r}\text { Harvesting } \\
\text { (men) }\end{array}$ & $\begin{array}{r}\text { Harvesting } \\
\text { (women) }\end{array}$ \\
\cline { 2 - 7 } Planting (men) & 1 & & & & & \\
Planting (women) & 0.123 & 1 & & & & \\
Off-peak (men) & 0.611 & 0.079 & 1 & & & \\
Off-peak (women) & -0.003 & 0.523 & 0.189 & & & \\
Harvesting (men) & 0.761 & 0.061 & 0.612 & -0.001 & 0.224 & \\
Harvesting & 0.239 & 0.669 & 0.155 & 0.425 & & \\
(women) & & & & & &
\end{tabular}


Most of the errors in the six equations estimated were positively correlated as shown in Table 2. The null hypothesis stating that the error terms across the six equations are uncorrelated was rejected at the $1 \%$ significance level. The significant correlation of errors in the six equations was as expected because working hours allocated by men and women across seasons have similar underlying determinants. Moreover, correlation coefficients between variables in Table 1 are less than 0.6 , so multicollinearity is not an issue.

Table 3: Factors affecting time allocation of men and women

\begin{tabular}{|c|c|c|c|c|c|c|}
\hline \multirow[b]{2}{*}{ Variables } & \multicolumn{3}{|c|}{ Men } & \multicolumn{3}{|c|}{ Women } \\
\hline & Planting & Harvesting & Off-peak & Planting & Harvesting & Off-peak \\
\hline \multirow[t]{2}{*}{$\ln ($ age $)$} & $-0.074^{*}$ & -0.036 & $-0.135 * *$ & -0.036 & -0.028 & $-0.112 * *$ \\
\hline & $(0.040)$ & $(0.045)$ & $(0.057)$ & $(0.037)$ & $(0.037)$ & $(0.050)$ \\
\hline \multirow[t]{2}{*}{ Literacy } & 0.045 & 0.045 & -0.003 & -0.018 & -0.012 & -0.033 \\
\hline & $(0.031)$ & $(0.033)$ & $(0.047)$ & $(0.048)$ & $(0.036)$ & $(0.064)$ \\
\hline \multirow{2}{*}{ Genderh } & $-0.107 * *$ & $-0.136^{* * *}$ & -0.047 & $0.071^{*}$ & 0.032 & 0.026 \\
\hline & $(0.044)$ & $(0.044)$ & $(0.064)$ & $(0.042)$ & $(0.029)$ & $(0.046)$ \\
\hline \multirow[t]{2}{*}{$\ln$ (family) } & -0.029 & -0.024 & $-0.064^{*}$ & 0.008 & 0.010 & 0.006 \\
\hline & $(0.024)$ & $(0.025)$ & $(0.035)$ & $(0.019)$ & $(0.017)$ & $(0.036)$ \\
\hline \multirow[t]{2}{*}{$\ln ($ labor $)$} & -0.014 & 0.006 & 0.002 & 0.018 & 0.008 & 0.032 \\
\hline & $(0.022)$ & $(0.025)$ & $(0.034)$ & $(0.023)$ & $(0.019)$ & $(0.031)$ \\
\hline \multirow[t]{2}{*}{$\ln (\mathrm{tlu})$} & $0.037^{*}$ & 0.001 & -0.012 & 0.019 & 0.032 & 0.023 \\
\hline & $(0.021)$ & $(0.029)$ & $(0.031)$ & $(0.023)$ & $(0.023)$ & $(0.033)$ \\
\hline \multirow[t]{2}{*}{$\ln ($ inct $)$} & -0.013 & -0.018 & 0.005 & 0.001 & 0.012 & $0.047 * *$ \\
\hline & $(0.018)$ & $(0.019)$ & $(0.027)$ & $(0.016)$ & $(0.015)$ & $(0.021)$ \\
\hline \multirow[t]{2}{*}{ SLMn } & 0.007 & 0.005 & $0.019^{*}$ & $0.015 * *$ & $0.014 * * *$ & $0.018 * *$ \\
\hline & $(0.006)$ & $(0.006)$ & $(0.010)$ & $(0.006)$ & $(0.005)$ & $(0.009)$ \\
\hline \multirow[t]{2}{*}{$\ln (\mathrm{SFI})$} & $0.471 * * *$ & $0.521 * * *$ & 0.286 & $0.338 * *$ & $0.267 * *$ & 0.161 \\
\hline & $(0.147)$ & $(0.163)$ & $(0.189)$ & $(0.151)$ & $(0.135)$ & $(0.202)$ \\
\hline \multirow[t]{2}{*}{$\ln ($ distance $)$} & 0.005 & -0.018 & 0.015 & 0.013 & 0.009 & 0.016 \\
\hline & $(0.023)$ & $(0.024)$ & $(0.038)$ & $(0.022)$ & $(0.019)$ & $(0.036)$ \\
\hline \multirow[t]{2}{*}{ AEZ } & -0.020 & -0.018 & -0.039 & -0.004 & -0.024 & 0.004 \\
\hline & $(0.020)$ & $(0.026)$ & $(0.034)$ & $(0.022)$ & $(0.020)$ & $(0.032)$ \\
\hline \multirow[t]{2}{*}{ Constant } & $4.421 * * *$ & $4.340 * * *$ & $4.505 * * *$ & $4.088 * * *$ & $4.211 * * *$ & $4.372 * * *$ \\
\hline & $(0.193)$ & $(0.207)$ & $(0.266)$ & $(0.194)$ & $(0.183)$ & $(0.264)$ \\
\hline R-squared & 0.106 & 0.081 & 0.058 & 0.086 & 0.086 & 0.068 \\
\hline Chi-squared & 34.97 & 26.10 & 18.33 & 27.74 & 27.88 & 21.48 \\
\hline p-value & 0.000 & 0.006 & 0.074 & 0.003 & 0.003 & 0.030 \\
\hline Observation & 295 & 294 & 295 & 295 & 295 & 295 \\
\hline \multicolumn{7}{|c|}{$* * \mathrm{p}<0.01, * * \mathrm{p}<0.05, * \mathrm{p}<0.1$} \\
\hline \multicolumn{7}{|c|}{ Standard errors in parentheses } \\
\hline & Sourc & $\mathrm{m}$ & urvey & & & \\
\hline
\end{tabular}




\section{Land fragmentation indicators}

LF indicators together affected hours worked by men during planting and harvesting seasons at the $1 \%$ and $5 \%$ significance levels, respectively, while did not affect hours worked by women throughout the seasons. Specifically, the agro-ecological zone and sum of non-overlapping distance to all plots from home did not have a significant effect on time allocated to work by both men and women. However, for the harvesting and planting seasons, a marginal change in the Simpson index increased working hours for women by about $0.3 \%$, while it increased working hours for men by almost $0.5 \%{ }^{4}$ (see Table 3 ).

Moreover, we examined hypotheses $A_{1}-A_{4}$ to show whether LF indicators separately affect the working hours of women differently than that of men. Hypothesis $A_{1}$, was not rejected for the non-overlapping distance to all plots and the agro-ecological zone. However, the hypothesis was rejected for the Simpson index at the 5\% significance level for both peak seasons, as shown in Table 4. We did not report hypotheses test results for the agro-ecological zone. Hypothesis $A_{2}$, was also rejected for the Simpson index for peak seasons at the $1 \%$ significance level, but the hypothesis was not rejected for the LF indicators distance and agro-ecological zone for all the seasons (see Table 4). For both men and women, the Simpson index increased hours worked during the peak seasons, implying that activities and round trips to various plots are timeconsuming during the peak seasons compared to the off-peak season. The findings are consistent with earlier theoretical arguments; for instance, McCall (1985) discussed that commuting time increases more when people travel to plots at a distance and back home every day to collect domestic necessities like firewood and fodder, particularly for women (McCall, 1985). Earlier studies also found that LF increases family labour use (Hung et al., 2007) and time of commuting (Blarel, Hazell, Place, \& Quiggin, 1992; Nguyen, Cheng, \& Findlay, 1996).

\section{Insert table 4 here}

${ }^{4}$ If $\ln y_{i}=\beta_{0}+\beta_{1} x_{i}+\beta_{2} \ln \left(z_{i}\right)+\varepsilon_{i}$, then $d y_{i} / d x_{i}=e^{\beta_{1}}-1$ and $d y_{i} / d z_{i}=\beta_{2}$ 
Table 4. Likelihood ratio test for hypotheses ${ }^{5}$

Women

Men

Hypothesis Lambda df p-value Decision Hypothesis Lambda df p-value Decision

\begin{tabular}{llllllllll}
\hline$A_{1}: \beta_{111}=0$ & 4.99 & 1 & 0.023 & Rejected & $A_{2}: \beta_{121}=0$ & 10.32 & 1 & 0.001 & Rejected \\
$A_{1}: \beta_{112}=0$ & 3.91 & 1 & 0.048 & Rejected & $A_{2}: \beta_{122}=0$ & 10.19 & 1 & 0.001 & Rejected \\
$A_{1}: \beta_{113}=0$ & 0.63 & 1 & 0.427 & Not rejected & $A_{2}: \beta_{123}=0$ & 2.31 & 1 & 0.129 & Rejected \\
$A_{1}: \beta_{211}=0$ & 0.35 & 1 & 0.540 & Not rejected & $A_{2}: \beta_{221}=0$ & 0.06 & 1 & 0.810 & Not rejected \\
$A_{1}: \beta_{212}=0$ & 0.21 & 1 & 0.650 & Not rejected & $A_{2}: \beta_{222}=0$ & 0.52 & 1 & 0.470 & Not rejected \\
$A_{1}: \beta_{213}=0$ & 0.19 & 1 & 0.670 & Not rejected & $A_{2}: \beta_{223}=0$ & 0.15 & 1 & 0.700 & Not rejected \\
$A_{4}: \beta_{111}=\beta_{112}$ & 0.28 & 1 & 0.590 & Not rejected & $A_{4}: \beta_{121}=\beta_{122}$ & 0.19 & 1 & 0.660 & Not rejected \\
$A_{5}: \gamma_{11}=0$ & 6.27 & 1 & 0.012 & Rejected & $A_{5}: \gamma_{21}=0$ & 1.23 & 1 & 0.267 & Not rejected \\
$A_{5}: \gamma_{12}=0$ & 6.93 & 1 & 0.009 & Rejected & $A_{5}: \gamma_{22}=0$ & 0.59 & 1 & 0.443 & Not rejected \\
$A_{5}: \gamma_{13}=0$ & 4.06 & 1 & 0.044 & Rejected & $A_{5}: \gamma_{23}=0$ & 3.77 & 1 & 0.052 & Not rejected \\
$A_{8}: \gamma_{11}=\gamma_{12}$ & 0.04 & 1 & 0.830 & Not rejected & & & & & \\
$A_{8}: \gamma_{11}=\gamma_{13}$ & 0.13 & 1 & 0.720 & Not rejected & & & & & \\
$A_{8}: \gamma_{12}=\gamma_{13}$ & 0.13 & 1 & 0.720 & Not rejected & & & & & \\
\hline
\end{tabular}

Source: Estimated from survey data

We extended the analysis for each LF indicator that had a significant effect on the working hours of women and men in a given season. For instance, we assessed hypotheses $A_{3}$ that states that Simpson index has the same impact on the mean hours worked by men and women per week for a given season. The hypothesis was rejected for the harvesting season but not rejected for planting season at the 5\% significance level, implying that the Simpson index affected the working hours of men more than women for harvesting season while it has an equal impact on working hours of men and women for the planting season (see Table 5).

\footnotetext{
${ }^{5}$ The subscripts of $\beta$ are as follows: If the first subscript is 1,2 or 3 it stands for Simpson index, distance or agroecological zone, respectively; if the second subscript is 1 or 2 it stands for women or men, respectively; and if the third subscript is 1, 2 or 3 it stands for planting, harvesting or off-peak season, respectively. For $\gamma$, if the first subscript is 1 or 2 it stands for women or men, respectively; and if the second subscript is 1,2 or 3 it stands for planting, harvesting or off-peak season, respectively.
} 
Table 5. Impacts of LF on the working hours of men and women ${ }^{6}$

\begin{tabular}{lllll}
\hline Hypothesis & Lambda & df & P-value & Decision \\
\hline$A_{3}: \beta_{111}=\beta_{121}$ & 0.56 & 1 & 0.45 & Not rejected \\
$A_{3}: \beta_{112}=\beta_{122}$ & 2.34 & 1 & 0.01 & Rejected \\
\hline
\end{tabular}

We also assessed hypothesis $A_{4}$, for LF indicators that had a significant effect on the working hours of men. The hypothesis was not rejected for the Simpson index, implying that the Simpson index equally impacts hours worked by women for both peak seasons. We also assessed the same hypothesis for men and found that the null hypothesis was not rejected. From hypotheses $A_{1}-A_{4}$ we can infer that the Simpson index has a significant gendered impact during the harvesting season, but other LF indicators do not indicate gender-biased effects on the working hours of men and women.

\section{Sustainable land management practices}

The estimation results of the SUR model presented in Table 3 show that the number of SLM practices deployed affected working hours of women for all seasons. As an illustrative example, when the number of SLM practices applied per farm increased by $1 \%$, women's working hours during the planting and harvesting season increased by $0.015 \%$ and $0.014 \%$, respectively. However, the number of SLM practices did not affect hours worked by men for all the seasons at the $5 \%$ significance level.

We also evaluated hypotheses $A_{5}-A_{6}$ to see whether SLM practices affect the working hours of women differently than that of men. The test results are presented in Table 4. The results show that hypothesis $A_{5}$, was rejected at the $1 \%$ and $5 \%$ significance level for the harvesting, planting and off-peak seasons respectively. However, the corresponding null hypothesis $A_{6}$ was not rejected. We could not extend the analysis further to hypotheses $A_{7}$ and

\footnotetext{
${ }^{6}$ Subscripts of $\beta$ and $\gamma$ can be read as indicated in footnote 2 .
} 
$A_{8}$ because the number of SLM practices applied did not have a significant effect on hours worked by men, but it had a significant effect on hours worked by women. The significant effect on hours worked by women and the insignificant effect on hours worked by men are incomparable. Therefore, the hypothesis $A_{7}$ was rejected in favour of the hypothesis that states that the mean effect of the number of SLM practices on working hours of women was higher than those of men. Regarding hypothesis $A_{8}$, the effect of the number of SLM practices applied on working hours of women did not vary from season to season. From the preceding results, we can infer that SLM practices are gendered in the Gamo Highlands of Ethiopia. These results are consistent with the findings of Tatlonghari and Paris (2013) that climate adaptation increased the work burden of women in the Philippines, as well as with other studies showing the existence of gendered climate change adaptation practices (Jin et al., 2015; Mersha \& Van Laerhoven, 2016).

\section{Conclusions}

This study argued that because of socially constructed roles and responsibilities of women and men (i.e., gender division of labour) and local conditions (i.e., notable LF), adaptation to climate change in the Gamo Highlands imposes more burdens on women than men. To explain this, we estimated a time allocation model and evaluated the effect of LF and the number of SLM practices on time allocated to work by men and women during two peak seasons (i.e., harvesting and planting) and the off-peak season.

The results indicated that Simpson index increased hours allocated to work by both men and women during the peak seasons. The results may imply that the area and the number of plots (i.e., Simpson index) aspects of LF are more powerful in increasing the working hours of both sexes than the distance dimension of LF. The working hours of women were significantly higher than that of men for all seasons, probably due to the gendered division of domestic labour, for instance, fetching domestic necessities from plots at a distance and the fact that some farm activities like adding manure are solely carried out by women. Moreover, the majority of household heads opined that LF increased the working hours of women more than that of men. However, the hypothesis tests show that LF (measured by the Simpson index) increased working hours of men during the harvesting season significantly more than it did for 
women. The household responsibility hypothesis (HRH) by Johnston-Anumonwo (1992) could explain the contrasts and why men worked for longer hours during harvesting season than women. According to the HRH, women commute shorter distances to work than men, as women shoulder more domestic work than men in Gamo communities. That is to say, a gender-skewed division of household labour leads to the commuting differential between men and women women harvest on closer plots than men so as to shoulder most of the domestic work. However, application of land management practices to deal with climate change and variability results in more hours of work for women and leaves working hours for men unaffected. The finding is consistent with earlier studies ( e.g., Jerneck, 2018; Jin et al., 2015; Smucker \& Wangui, 2016). The overall result indicates the existence of gendered adaptation practices in the Gamo Highlands. Although the impact of LF on working hours is biased towards a particular gender (towards men in this case), the application of SLM practices on fragmented farm fields to deal with climate change is gender-skewed (towards women in this case). Hence, if LF in the Gamo Highlands was less severe, the burden of adaptation on women would be lower.

This study has some caveats. First, we only used a single indicator of gender bias, hours worked per week in three seasons. There are of course many other indicators of the position of women in a society, such as gender gaps in non-farm earnings (Abdulai \& Delgado, 1999). Moreover, this study does not assess the impacts of adaptation on fragmented landscapes on food security, household income or health, but is rather strictly looking at time poverty. Moreover, socially constructed gendered division of labour and its consequences on the contribution of women to development is not addressed in this study, in future studies these should be taken into account. Second, we used cross-sectional data ignoring the effect of time; i.e., time varying explanatory variables could not be taken into account. So, we cannot see whether the position of women has improved over time or not. Finally, we ignored the division of working hours over different activities. Further studies can contribute by explaining how farm field dispersion and application of SLM practices affects hours allocated to paid work and to domestic work like child care, and by testing the validity of the HRH when women and men commute to work on multiple dispersed plots in all seasons.

Despite these caveats, we think this paper contributes to the discussion of the gendered effects of fragmentation and climate change adaptation. Reducing farm fragmentation 
through cooperative farming or voluntary bartering of plots between neighbouring farmers could help to solve the work hour loss associated with fragmentation. Socially constructed gender division of labour plays an important role in increasing women's working hours more than for men in Gamo communities, albeit this study focused on LF and SLM practices. Awareness creation about how this skewed labour division impacts the contribution of women to social development is important to involve men in activities that are considered as women's tasks. This could lead to a gradual reduction of the gendered division of labour. This effort could promote a more fair burden for men and women so that SLM practices will affect them more equally and that the women's contribution to development will be enhanced.

\section{References}

Abdulai, A., \& Delgado, C. (1999). Determinants of nonfarm earnings of farm-based husbands and wives in Northern Ghana (Vol. 4305). Washington D.C.: World Bank publications.

Alston, M. (2011). Gender and climate change in Australia. Journal of Sociology, 47(1), 53-70. doi:https://doi.org/10.1177/1440783310376848

Alston, M. (2013). Women and adaptation. Wiley Interdisciplinary Reviews Climate Change, 4, 351-358.

Bardasi, E., \& Wodon, Q. (2006). Measuring time poverty and analyzing its determinants: concepts and application to Guinea. In M. Blackden \& Q. Wodon (Eds.), Gender, time use, and poverty in subSaharan Africa (Vol. 73, pp. 75-95). Washingon D.C.: World Bank.

Birch, E.-R. (2005). Studies of the labour supply of Australian women: What have we learned? Economic Record, 81(252), 65-84. doi:https://doi.org/10.1111/j.1475-4932.2005.00211.x

Birch, R. E., Le, T. A., \& Miller, W. P. (2009). Household divisions of labour: Teamwork, gender and time. New York: Palgrave and Macmillan.

Björnberg, K. E., \& Hansson, O. S. (2013). Gendering local climate adaptation. Local Environment, 18(2), 217-232.

Blarel, B., Hazell, P., Place, F., \& Quiggin, J. (1992). The economics of farm fragmentation: Evidence from Ghana and Rwanda. The World Bank Economic Review, 6(2), 233-254. doi: https://doi.org/10.1093/wber/6.2.233

Bryan, E., Deressa, T. T., Gbetibouo, A. G., \& Ringler, C. (2009). Adaptation to climate change in Ethiopia and South Africa: Options and constraints. Environmental Science and Policy, 12( ), 413-426. doi:https://doi.org/10.1016/j.envsci.2008.11.002

Bryan, E., Ringler, C., Okoba, B., Roncoli, C., Silvestri, S., \& Herrero, M. (2013). Adapting agriculture to climate change in Kenya: Household strategies and determinants. Journal of Environmental Management, 114, 26-35. doi:https://doi.org/10.1016/j.jenvman.2012.10.036

Bunce, A., \& Ford, J. (2015). How is adaptation, resilience, and vulnerability research engaging with gender? Environmental Research Letters, 10(12), 123003.

Burchardt, T. (2008). Time and income poverty.

Burke, M., \& Lobell, D. (2010). Food security and adaptation to climate change: What do we know? In M. Burke \& D. Lobell (Eds.), Climate change and food security (pp. 133-153). Dordrecht: Springer. 
Burke, R., \& McAteer, T. (2007). Work hours and work addiction: The price of all work and no play. In L. P. Pamela \& C. G. Daniel (Eds.), Exploring the Work and Non-Work Interface (Research in Occupational Stress and Well-being (Vol. 6, pp. 239-273): Emerald Group Publishing Limited.

Cameron, A. C., \& Trivedi, P. K. (2005). Microeconometrics: methods and applications. UK: Cambridge University Press.

Cameron, A. C., \& Trivedi, P. K. (2009). Microeconometrics Using Stata (Vol. 2). College Station, TX: Stata Press.

Cannon, T. (2002). Gender and climate hazards in Bangladesh. Gender and Development, 10(2), 45-50. doi:https://doi.org/10.1080/13552070215906

Craig, L. (2005). The money or the care: A comparison of couple and sole parent households' time allocation to work and children. Australian Journal of Social Issues, 40(4), 521-540.

Demetriades, J., \& Esplen, E. (2008). The gender dimensions of poverty and climate change adaptation. IDS Bulletin 39(4), 24-31. doi:https://doi.org/10.1111/j.1759-5436.2008.tb00473.x

Denton, F. (2002). Climate change vulnerability, impacts, and adaptation: Why does gender matter? Gender \& Development, 10(2), 10-20.

Di Falco, S., Veronesi, M., \& Yesuf, M. (2011). Does adaptation to climate change provide food security? A micro-perspective from Ethiopia. American Journal of Agricultural Economics, 93(3), 825-842.

Doss, C. R. (2001). Designing agricultural technology for African women farmers: Lessons from 25 years of experience. World Development, 29(12), 2075-2092. doi:https://doi.org/10.1016/S0305750X(01)00088-2

Fernandes, E. C., \& Burcroff, R. (2006). Sustainable Land Management: Challenges, Opportunities, and Trade-offs. Washington, D.C.: World Bank.

Field, C. B. (2012). Managing the risks of extreme events and disasters to advance climate change adaptation: special report of the intergovernmental panel on climate change. UK: Cambridge University Press.

Hung, V. P., MacAulay, T. G., \& Marsh, P. S. (2007). The economics of land fragmentation in the north of Vietnam. The Australian Journal of Agricultural and Resource Economics, 51, 195-211. doi:https://doi.org/10.1111/j.1467-8489.2007.00378.x

Hours of Work (Industry) Convention, 1919 (No. 1), 2, International Labour Organization, 13 Stat. (1921).

Jabs, J., \& Devine, C. M. (2006). Time scarcity and food choices: an overview. Appetite, 47(2), 196-204. doi:https://doi.org/10.1016/j.appet.2006.02.014

Jayne, T. S., Yamano, T., Weber, M. T., Tschirley, D., Benfica, R., Chapoto, A., \& Zulu, B. (2003). Smallholder income and land distribution in Africa: implications for poverty reduction strategies. Food Policy, 28(3), 253-275. doi:https://doi.org/10.1016/S0306-9192(03)00046-0

Jerneck, A. (2018). Taking gender seriously in climate change adaptation and sustainability science research: views from feminist debates and sub-Saharan small-scale agriculture. Sustainability Science, 13(2), 403-416.

Jin, J., Wang, X., \& Gao, Y. (2015). Gender differences in farmers' responses to climate change adaptation in Yongqiao district, China. Science of the Total Environment, 538, 942-948. doi:https://doi.org/10.1016/i.scitotenv.2015.07.027

Johnston-Anumonwo, I. (1992). The influence of household type on gender differences in work trip distance. The Professional Geographer, 44(2), 161-169. doi:https://doi.org/10.1111/i.00330124.1992.00161.x 
Kawasaki, K. (2010). The costs and benefits of land fragmentation of rice farms in Japan. The Australian Journal of Agricultural and Resource Economics, 54, 509-526. doi:https://doi.org/10.1111/j.1467-8489.2010.00509.x

Kes, A., \& Swaminathan, H. (2006). Gender and time poverty in sub-Saharan Africa. In C. M. Blackden \& Q. Wodon (Eds.), Gender, time use, and poverty in sub-Saharan Africa (pp. 13-38). Washington, D.C.: World Bank.

Kotir, H. J. (2011). Climate change and variability in Sub-Saharan Africa: A review of current and future trends and impacts on agriculture and food security. Environment, Development and Sustainability, 13, 587-605.

Kurukulasuriya, P., \& Mendelsohn, R. (2008). A Ricardian analysis of the impact of climate change on African cropland (Vol. 2).

Maddison, D. (2007). The perception of and adaptation to climate change in Africa (Vol. 4308). In S. R. a. U. D. Team (Series Ed.).

Manjunatha, A., Anik, R. A., Speelman, S., \& Nuppenau, E. (2013). Impact of land fragmentation, farm size, land ownership and crop diversity on profit and efficiency of irrigated farms in India. Land Use Policy 31, 397- 405. doi:https://doi.org/10.1016/j.landusepol.2012.08.005

Marlene, R., \& Henry, D. (2002). Reducing risk and vulnerability to climate change in India: The capabilities approach. Gender and Development, 10(2), 78-83. doi:https://doi.org/10.1080/13552070215904

McCall, B. (1985). The significance of distance constraints in peasant farming systems with special reference to sub-Saharan Africa. Applied Geography 5, 325-345. doi:https://doi.org/10.1016/0143-6228(85)90011-6

Mersha, A. A., \& Van Laerhoven, F. (2016). A gender approach to understanding the differentiated impact of barriers to adaptation: Responses to climate change in rural Ethiopia. Regional Environmental Change, 16(6), 1701-1713. doi:doi: 10.1007/s10113-015-0921-z

Minu, H., \& Ulrike, R. (2009). Engendering the climate-change negotiations: experiences, challenges, and steps forward. Gender and Development, 17(1), 19-32. doi:https://doi.org/10.1080/13552070802696870

Mu, R., \& Van de Walle, D. (2011). Left behind to farm? Women's labor re-allocation in rural China. Labour Economics, 18, S83-S97.

Murray, U., Gebremedhin, Z., Brychkova, G., \& Spillane, C. (2016). Smallholder farmers and climate smart agriculture: technology and labor-productivity constraints amongst women smallholders in Malawi. Gender, Technology and Development, 20(2), 117-148. doi:https://doi.org/10.1177/0971852416640639

Nguyen, T., Cheng, E., \& Findlay, C. (1996). Land fragmentation and productivity in China in the 1990s. China Economic Review, 7(2), 169- 180. doi:https://doi.org/10.1016/S1043-951X(96)90007-3

Nigussie, Z., Tsunekawa, A., Haregeweyn, N., Adgo, E., Nohmi, M., Tsubo, M., . . . Abele, S. (2017). Factors influencing small-scale farmers' adoption of sustainable land management technologies in north-western Ethiopia. Land Use Policy, 67, 57-64. doi:https://doi.org/10.1016/j.landusepol.2017.05.024

Pachauri, K. R., \& Meyer, L. (2014). Synthesis Report: Contribution of working groups I, II and III to the fifth assessment report of the intergovernmental panel on climate change. Geneva, Switzerland: IPCC.

Parry, M., Canziani, O., Palutikof, J., van der Linden, P., \& Hanson, C. (2007). Climate Change 2007: Impacts, Adaptation and Vulnerability (Vol. 4). Cambridge: Cambridge University Press.

Peralta, A. (2009). Financing for Climate Change Mitigation and Adaptation in the Philippines. In. 
Rahmana, S., \& Rahman, M. (2008). Impact of land fragmentation and resource ownership on productivity and efficiency: The case of rice producers in Bangladesh. Land Use Policy, 26, 95103. doi:https://doi.org/10.1016/j.landusepol.2008.01.003

Shastri, A. (2014). Gender inequality and women discrimination. Journal of Humanities and Social Science, 19(11), 27-30. doi:https://doi.org/10.1080/13552070802696839

Smucker, A. T., \& Wangui, E. E. (2016). Gendered knowledge and adaptive practices: Differentiation and change in Mwanga district, Tanzania. Ambio, 45(3), 276-286. doi:10.1007/s13280-016-0828-z

Tatlonghari, G. T., \& Paris, T. R. (2013). Research, action and policy: Addressing the gendered impacts of climate change. Dordrecht: Springer Science \& Business Media.

Tennant, C. (2001). Work-related stress and depressive disorders. Journal of Psychosomatic Research, 51(5), 697-704. doi:https://doi.org/10.1016/S0022-3999(01)00255-0

Terry, G. (2009). No climate justice without gender justice: an overview of the issues. Gender \& Development, 17, 5-18.

Thomas, S. D., \& Twyman, C. (2005). Equity and justice in climate change adaptation amongst naturalresource-dependent societies. Global Environmental Change, 15, 115-124. doi:https://doi.org/10.1016/j.gloenvcha.2004.10.001

United Nations. (2005). Guide to producing statistics on time use: Measuring paid and unpaid work. In.

United Nations. (2015). The world's women 2015 trends and statistics. New York: United Nations

United Nations. (2018). Gender statistics Retrieved from: https://unstats.un.org/unsd/gender/timeuse/

Wright, P. (2007). Family size and the gendered division of unpaid work: Implications for fertility decisions in Australia. Australian Journal of Social Issues, 42(4), 513-529. doi:https://doi.org/10.1002/j.1839-4655.2007.tb00075.x

Zellner, A. (1962). An efficient method of estimating seemingly unrelated regressions and tests for aggregation bias. Journal of the American Statistical Association, 57(298), 348-368. 
